\title{
A IMPORTÂNCIA DA ESTRATÉGIA ORGANIZACIONAL PARA A CONFEDERAÇÃO BRASILEIRA DE VOLEIBOL
}

\section{Sávio Lourenço Souza}

\section{RESUMO}

O objetivo geral deste trabalho é analisar a estratégia organizacional desenvolvida por uma organização brasileira de administração esportiva, a Confederação Brasileira de Voleibol (CBV) nos últimos 30 anos, a partir da metodologia das "5 forças de Porter". Trata-se de um projeto de pesquisa descritivo analítico baseado em dados secundários relacionados a partir da década de 70 . Ficou estabelecido a análise da Confederação Brasileira de Voleibol como estudo de caso. Ao abordarmos o case da CBV foi possível detectar os ganhos que uma instituição de administração esportiva pôde obter a partir da definição de uma estratégia organizacional e, na seqüência, do desenvolvimento de um planejamento estratégico estruturado. Planejamento este que teve início há 30 anos baseado em uma estratégia inovadora que tinha como alicerce o entendimento do esporte como um negócio. Entretanto, os resultados alcançados não estão condicionados apenas ao fato de possuir um plano estratégico, tão importante quanto ter é saber executá-lo.

Palavras-Chave: Planejamento. Estratégico. Porter. Estratégia. Organizacional.

\begin{abstract}
The general objective of tihs article is to analyze the organizational strategy developed by a brazilian organization of sport management, the Confederação Brasileira de Voleibol (CBV) during last the 30 years, from the methodology of the " 5 forces of Porter". It is about na analytical project based on descriptive research in related secundary data since 70's decade. It was established the CBV analysis as the case to be study. Through the CBV case analyze was possible to detect the profits that a sport management organization could get from the definition of an organizational strategy and from the development of a structuralized strategical planning wich have been made 30 years ago, based in an innovative strategy that had as foundation the agreement of the sport as a business. However, the reached results are not conditional only to the fact to possess a strategical plan, because so important to develop a plan is to know to implement it.
\end{abstract}

Key-Words: Planning. Strategical. Porter. Strategy. Organizational. 


\section{REVISÃO BIBLIOGRÁFICA}

\section{Estratégia}

Por se tratar de entidades sociais que atuam em um ambiente complexo e dinâmico, relacionadas ao mercado produtor e consumidor de serviços esportivos, neste caso direcionado exclusivamente ao voleibol indoor, as organizações definem diretrizes (missão, visão e valores institucionais) que as orientem, no sentido de alcançar seus objetivos, sendo, desta forma, competitiva em seu segmento. 0 êxito nesta empreitada está diretamente relacionado à capacidade que as organizações possuem de definir uma estratégia eficaz. A estratégia é entendida como o plano de ação global que a instituição irá desenvolver, considerando fatores internos e externos, no sentido de atingir seus objetivos de longo prazo. A formulação da estratégia passa pelo processo de analisar o ambiente no qual uma determinada organização está inserida. Tomando-se os objetivos organizacionais, será possível traçar estratégias que possibilitem o alcance destes, a partir da compreensão efetiva da infra estrutura interna existente ( back office ), dos stakeholders envolvidos e do ambiente externo ( front office ).

A fim de ilustrar o conceito exposto, focado na análise do direcionamento de uma visão estratégica para o segmento esportivo, podemos citar William Sutton, Bernard Mullin e Stephen Hardy (2004). Os autores utilizam um plano de jogo para o desenvolvimento de um planejamento estratégico. Neste contexto, desenvolvem uma analogia relacionado a preparação de uma equipe objetivando a participação em uma competição de alto nível. Os treinadores avaliam pormenorizadamente os seus jogadores para saber o talento com o qual eles irão trabalhar, investigando cuidadosamente os oponentes, o ambiente externo, e conseqüentemente desenvolvendo as táticas e manuais de jogo, analogia perfeitamente coerente com a visão do planejamento estratégico.

\section{Planejamento Estratégico}

Processo gerencial no qual a organização irá estabelecer um conjunto de ações estruturadas, baseada em suas diretrizes e nos fatores internos e externos à empresa, na perspectiva de atingir seus objetivos a médio e longo prazo. Segundo Kotler (2006) o planejamento estratégico compreende algumas etapas a saber:

Missão do negócio; Análise SWOT; Definição de metas; Formulação de estratégias, Elaboração de Programas e Implementação; Feedback e Controle.

Anteriormente foi ressaltada a definição de diretrizes como ponto primordial neste processo. Dentre elas está a missão. Ela irá dizer o propósito da organização, qual a sua razão de existir, o que ela se propõe a oferecer ao mercado. Este é um elemento fundamental mas não suficiente, ele permite que todo o processo restante seja convergente, diminuindo o risco de perda do foco na elaboração do plano.

A análise SWOT compreende a avaliação global das forças, fraquezas, oportunidades e ameaças. As forças e fraquezas da organização estão mais voltadas para características internas. 0 primeiro diz respeito aos fatores que são destaque para a organização permitindo que os mesmos sejam utilizados e até explorados por se tratarem de características altamente positivas e poderão gerar bons resultados. A segunda diz respeito aos fatores internos que precisam ser trabalhados no sentido de melhora-los, pois não são vistos como confiáveis na perspectiva de gerar bons resultados. Pode-se dizer que são características em que a empresa 
é vulnerável ou que apresenta desempenhos inferiores as demais de seu segmento.

Oportunidades e ameaças estão relacionadas a fatores do ambiente no qual a empresa está inserida. A primeira compreende um cenário que apresenta condições favoráveis a novos investimentos. A segunda compreende um cenário que apresenta condições desfavoráveis a novos investimentos.

A definição de metas é importante para que se estabeleça um ponto mensurável a ser atingido. Estes irão nortear a formulação da estratégia. 0 conjunto de metas estarão necessariamente convergindo para o cumprimento da missão do negócio.

A formulação de estratégias compreende um conjunto de ações definidas pela alta administração da organização para que se alcance as metas estabelecidas. 0 caráter defensivo ou ofensivo das ações a serem executadas irá depender da estratégia absorver um caráter defensivo ou ofensivo, respectivamente. A partir das informações levantadas nas etapas preliminares do planejamento estratégico (missão, análise SWOT e definição de metas) a organização terá subsídios para formular a sua estratégia de ação a qual deverá ser o meio ótimo para o cumprimento da missão do negócio e o caminho mais eficiente para atingir seus objetivos.

A implementação de programas diz respeito a execução da estratégia elaborada. Os programas a serem implementados estão estreitamente ligados a estratégia definida. Todas as ações formuladas na estratégia serão colocadas em prática neste item.

Implantando um sistema de feedback e controle uma organização terá condições de acompanhar os resultados e monitorar novos acontecimentos nos ambientes interno e externo. A partir deste sistema será possível mensurar os resultados internos e externos obtidos com a implantação dos programas e também monitorar as constantes alterações do mercado.

Estes fatores não estão relacionados de forma linear, ou seja, há uma ligação entre suas extremidades. Para melhor entendermos sua aplicação é ideal que seja tomada uma visão do processo de forma cíclica, onde o feedback irá gerar resultados que implicará na revisão da análise SWOT e, em alguns casos podem impactar também a missão do negócio.

\section{Método das 5 Forças de Porter}

Segundo PORTER, Michael (2004), a essência da formulação de uma estratégia competitiva é relacionar uma empresa ao seu meio ambiente externo. Mesmo abrangendo tanto forças sociais como econômicas, o aspecto principal deste meio ambiente é a estrutura da industria na qual a empresa está inserida. Este conceito levou o estudioso a elaborar o modelo das "5 forças de Porter", onde diferentes agentes integrantes de qualquer indústria interagem entre si, de diferentes formas, numa relação continua de causa e efeito, exercendo assim um papel fundamental para a elaboração da estratégia em uma companhia. Estes agentes são:

\section{Compradores:}

O público consumidor do bem ou serviço produzido. Para ter sucesso é fundamental que uma instituição conheça bem o seu público alvo. Conhecendo o perfil dos seus compradores a tarefa de elaborar um produto atraente e que atenda aos desejos do cliente se torna mais fácil.

Além disso, a identificação do grupo de compradores, levantando suas características quanto 
a classe social, poder de consumo, faixa etária, entre outros fatores sócio econômico, é importante para a formação do preço do produto, ou serviço.

\section{Entrantes:}

Caracterizam-se, inicialmente, por ser um concorrente a mais, para o mercado implicará preocupação adicional para as empresas de uma determinada indústria. Por serem novas em um segmento específico, surgem com fôlego e, na maioria das vezes, com grande volume financeiro, sustentando o investimento no empreendimento. Por tudo isso, e por concorrerem com organizações já existentes são capazes de criar novos paradigmas no negócio gerando mudanças substanciais na maneira como o negócio é conduzido. Geralmente são novas empresas em um determinado segmento do mercado, pode ser também uma nova empresa criada a partir de uma fusão, onde uma empresa soma seu capital com outra de segmentos diferentes passando a atuar como uma única empresa com novas características.

\section{Substitutos:}

Produtos ou serviços substitutos apresentam-se como um alternativa ao consumidor no lugar de produtos ou serviços já existentes, desempenhando a mesma função. Na maioria das vezes os substitutos prevalecem sobre seus similares em função da baixa relação preçodesempenho ou quando são produzidos por empresas altamente lucrativas.

\section{Concorrentes:}

Empresas que competem por um mesmo espaço no mercado, seja pela comercialização de produtos ou serviços similares ou por atuarem dentro de um mesmo segmento.

\section{Fornecedores:}

Tem o poder de negociação através do produto ou serviço prestado, podendo alterar seu preço ou as características do bem fornecido. A pouca variedade de fornecedores, a alta importância de um bem para uma indústria específica e a diferenciação do produto fornecido são fatores que potencializam o poder exercido pelos fornecedores.

\section{DESENVOLVIMENTO DA ESTRATÉGIA EM UMA INSTITUIÇÃO DE PRÁTICA ESPORTIVA - ESTUDO DE CASO CBV}

\section{Histórico}

O aprofundamento da compreensão do significado do setor esportivo como integrante da concorrida indústria do entretenimento, neste caso relacionada à modalidade do voleibol indoor, no contexto de sua sustentabilidade e participação no mercado, originou uma nova percepção relacionada a gestão esportiva por parte dos administradores da Confederação Brasileira de Voleibol (CBV) a partir da década de 70, quando termos relacionados a publico alvo, sustentabilidade, competitividade e unidade de negócios foram introduzidos. Ao assumir o comando do voleibol nacional nesta década, Carlos Arthur Nuzman implantou novas práticas de gestão. Observa-se que a gestão Nuzman além da busca permanente pela profissionalização da CBV, cujos reflexos seriam sentidos inclusive nas federações estaduais, atuou basicamente em duas vertentes. A primeira objetivando viabilizar uma tradicional fonte de receita, já adotada fortemente pelas instituições americanas e européias, relacionada ao patrocínio, tanto das empresas públicas como privadas, proporcionando visibilidade das marcas e associação destas com todos os atributos positivos que o voleibol proporciona, 
possibilitando assim um aumento significativo de receitas. $\mathrm{Na}$ segunda, oferecendo uma infraestrutura adequada para o desenvolvimento de novos atletas, técnicos, arbitragens e tudo aquilo que pudesse agregar valor, inclusive relacionado a profissionalização das 27 federações estaduais, possibilitando atingir um estágio básico satisfatório para o fortalecimento da prática em todos os segmentos, de competições de melhor nível, do surgimento permanente de novos atletas de qualidade, proporcionando consequentemente 0 fortalecimento do voleibol indoor.

A introdução da obrigatoriedade da Educação Física nas escolas de primeiro e segundo grau, inclusive nas universidades, estabelecia-se como um dos alvos da Confederação, entendida como um dos grandes campos de atuação para a prática do voleibol. Estas duas vertentes apontam para uma visão estratégica do voleibol brasileiro. (ISTVAN K. KASZNAR e GRAÇA A. S. Fo, 2006)

Na década 80, capacitação empresarial e estrutural se tornou ponto fundamental e prioritário na estratégia da organização. Os resultados, tanto a nível nacional, através do incremento das competições regionais e das competições nacionais se tornavam evidentes, assim como das conquistas internacionais, como o vice campeonato mundial e olímpico na década de 80, através da geração de grandes atletas como Bernard, Xandó, Fernandão, Bernardinho, e diversos outros. Ainda na década de 80 foi elaborado um novo desenho organizacional onde a $\mathrm{CBV}$, como órgão central teria ao seu redor as Federações atuando de forma independente nos seus respectivos Estados, mas subordinadas à CBV no que diz respeito as diretrizes que norteiam as suas ações. Desta forma permitiu-se maior descentralização na tomada de decisões nas Federações e ao mesmo tempo, maior centralização quanto ao comando do voleibol em território nacional. A partir da década de 90 , já na gestão do atual presidente da Confederação Brasileira de Voleibol, Dr. Ary Graça, percebeu-se a necessidade de se criar uma estrutura organizacional que permitisse uma maior produtividade das atividades exercidas pela entidade e assim torná-la competitiva, inclusive internacionalmente.

Adicionalmente, a CBV procurou adotar o conceito mercadológico da segmentação de mercado, dividindo o esporte por tipo e público-alvo, introduzindo inclusive o conceito de unidade de negócio, que trabalharia focado na performance e rendimento das diferentes práticas existentes no voleibol.

A partir do ano 2000, a visão do business foi, podemos afirmar, consolidada. 0 entendimento do esporte como negócio se estabelecia fundamentado em planejamentos estratégicos. A busca pela superação permanentemente se estabelecia como cultura organizacional. Esta consolidação extrapolou o campo dos negócios, gerando reflexos nas quadras, com a conquista de títulos em série pelas seleções principais do masculino e do feminino. Abaixo, no quadro de títulos, podemos visualizar esta ascensão que começou já na década de 1990 com os primeiros títulos fora do continente sul-americano, mas que se consolidou de fato a partir de 2000, onde o Brasil estabeleceu-se como uma potência no esporte, tendo conquistado diversos títulos importantes, em anos seguidos. 
Quadro 1: Evolução dos títulos

\begin{tabular}{|c|c|c|c|c|}
\hline Década & Ano & Masculino & Ano & Feminino \\
\hline 70 & $\begin{array}{c}1971,73,75 \\
77 \text { e } 79\end{array}$ & Sul-Americano & & \\
\hline \multirow[t]{2}{*}{80} & $\begin{array}{c}1981,83,85, \\
87 \text { e } 89\end{array}$ & Sul-Americano & 1981 e 83 & Sul-Americano \\
\hline & 83 & Pan-Americano & & \\
\hline \multirow[t]{5}{*}{90} & 1998 e 99 & Copa América & 1995 & Montreux Volley Masters \\
\hline & 1993 & Liga Mundial & 1999 & Pan-Americano \\
\hline & 1992 & Olimpíadas & $\begin{array}{c}1991,95,97 \mathrm{e} \\
99\end{array}$ & Sul-Americano \\
\hline & $\begin{array}{c}1991,93,95 \\
97 \text { e } 99\end{array}$ & Sul-Americano & 1994,96 e 98 & Grand Prix \\
\hline & 1997 & Copa dos Campeões & & \\
\hline \multirow[t]{7}{*}{2000} & 2001 & Copa América & 2005 e 2006 & Montreux Volley Masters \\
\hline & 2003 & Copa do Mundo & 2001,03 e 05 & Sul-Americano \\
\hline & $\begin{array}{c}2001,03,04, \\
05 \text { e } 06\end{array}$ & Liga Mundial & 2005 & Copa dos Campeões \\
\hline & 2002 e 06 & Campeonato Mundial & 2004,05 e 06 & Grand Prix \\
\hline & 2004 & Olimpíadas & & \\
\hline & 2001,03 e 05 & Sul-Americano & & \\
\hline & 2005 & Copa dos Campeões & & \\
\hline
\end{tabular}

\section{A Estratégia Da Cbv}

A partir do entendimento do esporte como um negócio a Confederação Brasileira de Voleibol viu-se diante da necessidade de elaborar uma estratégia organizacional que a torna-se competitiva em seu segmento de mercado, sendo de fundamental importância na construção desta história de sucesso. Entender a sua concepção e seu desenvolvimento ajudarão na percepção da sistemática que está por detrás da elaboração de um plano estratégico em uma organização esportiva. Em seu livro Estratégia Empresarial, KASZNAR, Istvan K. e FILHO, Ary S. Graça (2004) destacam 5 pontos importantes que serviram de base para implementar, o que eles chamaram de "postura estratégica" adotada pela CBV.

\section{A Compreensão Do Voleibol Como Um Negócio}

A percepção do voleibol como um negócio foi ponto fundamental para a adoção de uma estratégia empresarial. A partir desta percepção inicial algumas premissas foram sendo estabelecidas como, definição da missão, metas e objetivos do negócio, dispor de um corpo diretivo capacitado e comprometido com a busca da perfeição em suas atribuições, captar para a organização pessoal com capacidade de antever oportunidade futura, aceitar e praticar o trabalho terceirizado para que se mantenha o foco no próprio negócio, passando a terceiros as atividades que não forem fundamentais para a atividade fim do setor, entre outras 
premissas que foram igualmente importantes para implementar esta mudança na estrutura da CBV.

\section{Gerar Benefícios Claros Aos Seus Parceiros}

Dar retorno aos seus investidores, através do número de vitórias. Com o intuito de fortalecer o vinculo com investidores e parceiros atuais, sem perder de vista potencias colaboradores, foi estabelecido que os resultados obtidos em quadra serviriam de parâmetro para medir o sucesso do planejamento estratégico adotado. Segundo sua estratégia, vitórias em quadra atrairiam mais vitórias fora dela. Isto procede ao consideramos que o retorno de mídia espontânea é bastante relevante para os seus parceiros. Além disto, ficaria claro para os investidores que os seus recursos estão sedo bem aplicados, gerando resultado prático, indiscutíveis e de grande repercussão.

\section{Gestão estratégica.}

A Confederação estava alinhada com o planejamento definido, comprometida com a sua execução, definição de controles e eventuais revisões deste plano, tendo em vista o alcance dos objetivos de longo prazo, em outras palavras, a conquista de títulos em competições futuras. Para tanto, ela absorveu a proposta de pensar no todo organizacional e de nortear os rumos da organização a partir das premissas estabelecidas, levando-se em conta o cenário no qual a entidade está inserida.

\section{Traçar Uma Estrutura Empresarial}

Decidiu-se implantar uma estrutura empresarial que pudesse dotar a organização de maior flexibilidade e eficiência, principalmente nas questões operacionais. Optou-se então pelo modelo de Unidades Estratégicas de Negócios. Estas atuam de maneira independente mas sem escapar de uma hierarquia central, no que diz respeito as atribuições e objetivos a serem alcançados por cada unidade. Este comando central também é responsável por liberar os meios e provê formas de se alcançar os objetivos, resultados e metas da Unidade. As Unidades Estratégicas da CBV devem evoluir para tornar-se autônoma financeiramente, são elas: Competições Nacionais, Seleções, Vôlei de Praia, Eventos e Viva Vôlei.

A estrutura presidencial, diretiva, de aconselhamento, gerencial, administrativa e operacional (macroestrutura organizacional) deve ser leve, flexível e enxuta para que se encurte a distância entre a decisão estratégica e a operacionalização das ações.

\section{Capacitação profissional}

Pensando de dentro para fora, a CBV identificou a necessidade de trabalhar na capacitação de seus profissionais para que o coletivo fosse favorecido. Ou seja, a excelência da organização está na capacidade de seus colaboradores de gerar bons resultados. Com isso tem-se uma cultura permanente de treinamento para constante atualização de seus funcionários. Da mesma forma a organização é entendida, de acordo com seus dirigentes com uma perfeita learning and teaching organization, uma empresa aprendiz, capacitada a transmitir o que aprende em troca de conhecimentos maiores. (ISTVAN K. KASZNAR e GRAÇA A. S. Fo , 2006)

\section{ANÁLISE DA ESTRATÉGIA DA CBV A PARTIR DAS “5 FORÇAS DE PORTER”}

Após visualizarmos algumas das premissas estabelecidas pela Confederação Brasileira de Voleibol ao desenvolver a seu estratégia empresarial, a partir dos 5 pontos principais 
apontados pelo seu atual presidente, iremos analisá-las utilizando o método das 5 forças de Porter. Com esta metodologia podemos fazer uma análise dentro de um contexto competitivo na indústria do esporte. Citaremos os agentes da indústria que exercem influência na organização, segundo Porter e quais as causas e efeitos de suas ações, que impactam o órgão máximo do voleibol nacional. Adicionalmente, ainda sob o aspecto da competitividade através dos agentes da indústria, iremos verificar algumas das ações executadas pela CBV, procurando entender suas razões e os objetivos esperados com cada ação praticada.

Lembrando que estas ações seguem o escopo definido no plano estratégico, não sendo assim elaboradas e executadas de forma aleatória.

\section{Compradores:}

A partir da compreensão do esporte como um negócio, a CBV encomendou pesquisas de mercado com o intuito de levantar o perfil dos consumidores da modalidade, bem como suas preferências, motivações, interesses, valores e as objeções a respeito do vôlei.. De posse destes dados nasceu, recentemente o Projeto sócio Torcedor, um projeto inovador, considerando o universo dos esportes "amadores" no Brasil. 0 projeto Sócio Torcedor busca cativar novos torcedores, institucionalizar os atuais e torna-los compradores, consumidores do produto voleibol e suas variantes. Mediante o pagamente de mensalidade o torcedor terá desconto na compra de ingressos para os jogos da Seleção Brasileira (feminina e masculina) e na compra de produtos oficiais licenciados pela CBV, além de contar com facilidades como a visita às instalações da seleção brasileira em Saquarema e tirar fotos com os jogadores da seleção, entre outras vantagens. Com a institucionalização destes "sócios" a Confederação deu forma a um banco de dados, onde é possível levantar informações valiosas no que diz respeito a formação de preço, desenvolvimento de novos produtos, praça de atuação, entre outros pontos fundamentais para seu fortalecimento competitivo.

\section{Novos Entrantes}

A estrutura gerencial flexível e ágil da Confederação permitiu que há poucos anos atrás ela se preparasse para enfrentar a eminência de novos entrantes no voleibol, por meio de uma iniciativa inovadora em nível de gestão no esporte brasileiro.

Por volta da década de 90 o sucesso da NBA, notabilizou uma fórmula usada há muito tempo nos esportes praticados nos Estados Unidos como um todo. A utilização de Ligas Independentes com a responsabilidade de representar um grupo em determinado esporte, ficando ainda responsável, entre outras coisas, por gerenciar os campeonatos que reunião os seus associados. Com a notoriedade do fato o modelo passou a ser considerado por muitos no Brasil, como uma alternativa para alavancar o esporte "amador". A Liga estaria desvinculada às Federações ou Confederações sendo gerida por um grupo escolhido pelas entidades que iriam compor a Liga. A possibilidade da perda de poder pela confederação ascendeu o sinal de alerta. A Confederação Brasileira de Vôlei resolveu se mexer e, num passo ousado criou a Superliga de Vôlei, campeonato nacional de clubes (masculino e feminino) que corresponde a divisão de elite do voleibol nacional. Esta foi uma medida tomada como uma forma de ofuscar qualquer levante na direção de se formar um grupo alternativo para gerir o voleibol nacional.

\section{Substitutos}

Competir com o futebol no Brasil é tarefa praticamente impossível para qualquer esporte. Por isso tem-se claramente, a consciência de que o vôlei deve lutar pelo posto de $2^{2}$ esporte no gosto dos brasileiros, sem dar espaço para que outros esportes ocupem esta posição e este é 
um dos focos que norteiam a direção estratégica adotada pela entidade. Esta batalha se torna mais intensa a medida que ídolos surgem repentinamente e conquistam o público angariando novos amantes para alguns esportes. Assim foi com Aurélio Miguel no fim da década de 80 com o judô, Gustavo Borges, no início dos anos 90 com a natação, Gustavo Kuerten no fim da década de 90 e início do século XXI com o tênis e mais recentemente com Daiane dos Santos com a Ginástica Olímpica. Neste sentido a CBV tem trabalhado para ampliar as ações entre os mais jovens, com o intuito de gerar uma maior identificação do jovem com o esporte desde cedo, já na fase adolescente. Isto é feito através da organização de Campeonatos Nacionais para as categorias de base. As competições são feitas anualmente, e envolve as federações de todo o país, sendo bastante difundido e com amplo amparo de divulgação pela própria Confederação. Adicionalmente, o projeto Sócio-Torcedor colabora neste sentido, possibilitando maior interação dos amantes da modalidade aos jogos da Seleção Brasileira.

\section{Concorrentes}

A importância de manter-se atualizada em relação à indústria do esporte, suas demandas, concorrências e perspectivas, a preocupação em criar uma estrutura organizacional flexível e a necessidade de gerar benefícios claros a seus parceiros foram fatores primordiais para o fortalecimento da Confederação perante seus concorrentes. A área de marketing da CBV foi concebida para, entre outras atribuições não menos importantes, estudar, pesquisar e contratar pesquisas de mercado que venham a gerar subsídios para que se possa ter um diagnóstico fidedigno e atualizado a respeito do ambiente externo no qual a instituição está inserida. Desta forma ela absorve dados necessários para observar a movimentação de seus concorrentes, como, futebol, basquete, natação, entre outros que não se restringem a modalidades esportivas, mas que também se inserem na indústria do entretenimento, tais como, internet, cinema, vídeo games e etc. A adoção de uma estrutura organizacional flexível, através de Unidades de Negócios, permitiu à $\mathrm{CBV}$ um maior preparo na disputa diária por consumidores com seus concorrentes, pois possibilitou maior agilidade não só na tomada de decisões mas também na operacionalização destas.

\subsection{FORNECEDORES}

Dentre as ações implementadas a partir da percepção do voleibol como um negócio, estabeleceu-se a necessidade de focar as atividades da CBV no negócio principal, optando pela terceirização de diferentes atividades. Podemos citar um exemplo de sucesso no fornecimento de material esportivo para as seleções de todas as categorias. A Olympikus, fornece o material esportivo utilizado pelos atletas das seleções desde 1997, esta parceria envolve 13.800 itens (dentre eles, tênis, camisas, shorts, agasalhos, bonés, meias, etc.) por ano. A parceria não se restringe a um trabalho de fornecimento e exposição da marca. Os atletas estabelecem uma comunicação permanente no sentido de aperfeiçoar o material utilizado, fazendo com que a empresa de material esportivo utilize o voleibol como um laboratório para testar novos produtos.

Adicionalmente, a adoção do Sistema de Registro serviu de suporte para a execução eficiente de uma gestão estratégica, um dos cinco pilares que sustentaram a implementação, da "postura estratégica" na Confederação de Vôlei. Neste sistema é inserido, entre outros dados, informações dos fornecedores da CBV, os produtos oferecidos, preços praticados, contatos, com quais outras instituições possui vinculo contratual, etc. A partir deste sistema de registro a alta administração passa a tomar decisões estratégicas de forma mais segura. 


\section{CONCLUSÃO}

Ao abordarmos o case da Confederação Brasileira de Voleibol foi possível detectar os ganhos que uma instituição de administração esportiva pôde obter a partir da definição de uma estratégia organizacional e, na seqüência, do desenvolvimento de um planejamento estratégico estruturado.

Com a utilização do modelo das "5 forças de Porter" na análise da estratégia organizacional desenvolvida pela Confederação, simplificou-se a compreensão das diferentes ações colocadas em prática ao longo dos anos, visualizando-as de um ponto de vista estratégico e competitivo. Desta forma pudemos entender como cada ação estava relacionada, não apenas às forças que compõe uma indústria, bem como parte integrante de uma estratégia organizacional estruturada, concebida pela alta administração, neste caso a indústria do entretenimento, mais especificamente no segmento esportivo. Pudemos identificar como cada passo dado pela instituição estava diretamente relacionado a uma das 5 forças representadas pelo modelo. Evidenciou-se que durante os últimos 30 anos, período de análise compreendido por este trabalho, a CBV soube desenvolver o seu plano de maneira excelente, extremamente eficiente e com um profissionalismo raro, principalmente no âmbito da indústria de esporte no Brasil.

A crescente evolução dos resultados obtidos dentro das quadras pelas seleções brasileiras, no masculino e feminino,desde a década de 70, consolidou o sucesso da estratégia adotada pela CBV e fortaleceu a defesa da importância exercida pela elaboração e execução eficiente de uma estratégia organizacional eficaz dentro do planejamento estratégico na perspectiva da gestão organizacional, devendo ser utilizada também no segmento esportivo.

\section{BIBLIOGRAFIA}

PORTER, Michael E. Estratégia Competitiva: técnicas para análise de indústrias e da concorrência. 2. ed. Rio de Janeiro: Elsevier, 2004.

KASZNAR, Istvan Karoly; GRAÇA Foo, Ary S. Estratégia Empresarial: Modelo de gestão vitorioso e inovador da Confederação Brasileira de Voleibol. São Paulo: M. Books, 2006.

CHIAVENATO, Idalberto. Administração nos novos tempos. $2^{\underline{a}}$ ed. Rio de Janeiro: Campus, 1999.

MULLIN, Bernard J.; HARDY, Stephen; SUTTON, William A. Marketing Esportivo. $2^{\underline{a}}$ ed. Porto Alegre: Artmed/Bookman, 2004

CBV . VOLEI.ORG.BR. Disponível em: <http://www.volei.com.br> Acesso em 12 de dezembro de 2006. 